\title{
THD Minimization in Cascaded H-Bridge Inverter using Optimal Selective Harmonic Elimination.
}

\author{
K. Venkateswararao, G. Joga Rao
}

\begin{abstract}
Cascaded structured multilevel inverters are gaining lot of importance due to their simple structure and easiness in implementation. In this paper, the optimum selective harmonic elimination method is employed for a nine level inverter to suppress the selected lower order harmonic, which reduces the total harmonic distortion of the inverter considerably. The Newton rapson algorithm is employed in finding the switching angles that minimizes certain lower order harmonics. The order of the harmonics that are eliminated are third, fifth, and seventh harmonics. All the simulation results included for a nine level inverter using SIMULINK. Index Terms: Nine level MLI, Control of inverter, Modular Inverter.
\end{abstract}

Key Words: THD, optimum angles, Iterative methods.

\section{INTRODUCTION}

Even though lots of topologies are developed in the power electronics area, power quality is still not achieved appropriately. The quality of the output that is generated at the load terminals of the MLI is as low as possible. At very large number of levels, the THD is generally very low, but it is not practical to increase the number of levels in inverter due to the increased switching loss, increased number of components, and the complexity of the circuits like size increases. It is always suggestible to achieve good quality output voltage with low number of levels in a MLI. If the number of levels in a MLI is fixed, then the other factor that affects the quality of the output voltage is the control method that is employed in the MLI. These control techniques are usually known as modulation methods in MLIs.

Several types of modulation methods are available in literature. These methods are broadly classified based on the switching frequency of the main switches in MLIs. The former is the high frequency methods and the later is the fundamental frequency methods. The SPWM, space vector modulation, trapezoidal modulation etc are the high frequency methods, where as the NLC, space vector control etc are the examples for fundamental frequency methods.The main drawbacks of the high frequency methods are the high switching loss due the increase in switching frequency. Whereas the loss is less with the fundamental frequency modulation methods.

Manuscript received on May 23, 2021.

Revised Manuscript received on July 26, 2021.

Manuscript published on 30 July, 2021.

* Correspondence Author

Mr.K Venkateswara Rao*, Pursuing MTech, Department of Power Electronics, Raghu Institute of Technology (Autonomous) Visakhapatnam (Andhra Pradesh), India.

Dr. G Joga Rao, Associate Professor, Department of EEE, Raghu Institute of Technology (Autonomous) Visakhapatnam (Andhra Pradesh), India.

(C) The Authors. Published by Blue Eyes Intelligence Engineering and Sciences Publication (BEIESP). This is an open access article under the CC BY-NC-ND license (http://creativecommons.org/licenses/by-nc-nd/4.0/)

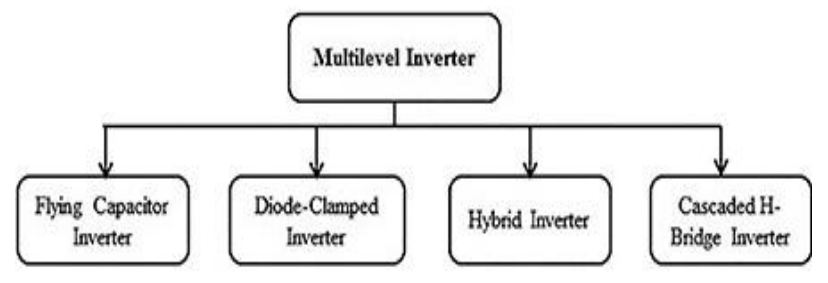

Figure 1 Classification of Multilevel Inverters.

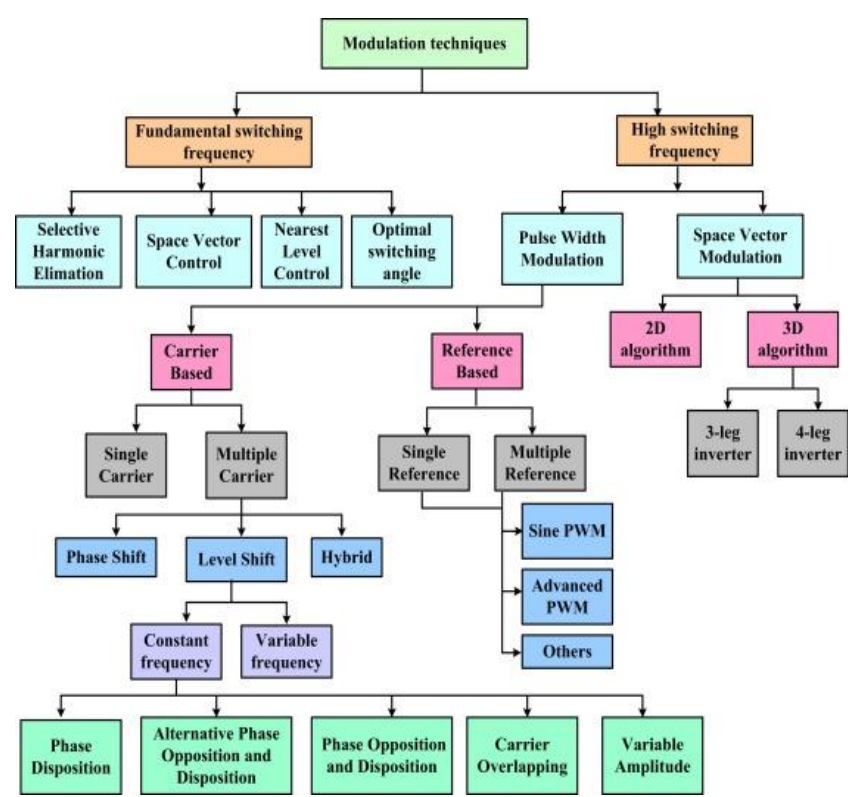

Figure 2 Classifications of Modulation Methods.

The above figure 1 and figure 2 shows the various types of multilevel inverters, and types of modulation methods respectively.

Even though there are many types in modulation methods, the aim of all the methods is to achieve the maximum possible reduction in THD of the voltage. But, THD is the total effect of individual harmonic components, which means it is a combination of all the harmonic components in a waveform. If the individual harmonic components which are having high in magnitude are removed then it improves the voltage quality and reduces the THD in waveform. But, all the modulation methods mostly not have control over the individual harmonic components. It requires a special method to reduce the selected harmonic component from all the components that are available.

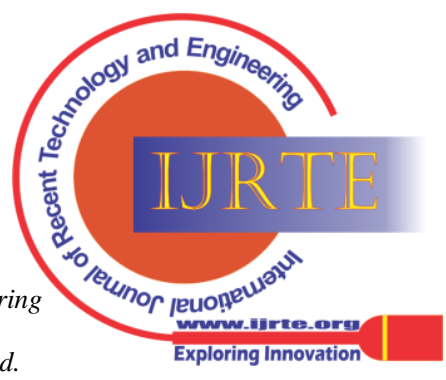


The only method which is having the feature of control of all the harmonics individually is the selective harmonic elimination or mitigation technique. With this method, it is possible to reduce or mitigate the any harmonic that is available in the waveform. This method can be applied to any inverter with any number of levels. It is popularly known as SHE or SHEPWM.

In this paper, the optimum SHE method is applied to a nine level inverter which is based on the CHB topology. The harmonics eliminated are third order, fifth order, and seventh order harmonics.

\section{OPTIMUM SELECTIVE HARMONIC ELIMINATION}

This method/technique requires following steps to find the optimal switching angles to reduce the corresponding harmonics from the voltage waveform. Various steps involved in this method are

- Problem formulation.

- Writing the final equations.

- Solving the non linear equations using some method.

- Generating the gate pulses according to the switching angles obtained.

\subsection{Problem Formulation}

To formulate the problem, the very first step is to follow the nature of the output voltage waveform, which is shown below in Figure 3. The wave form is quarter wave symmetry with much number of steps.

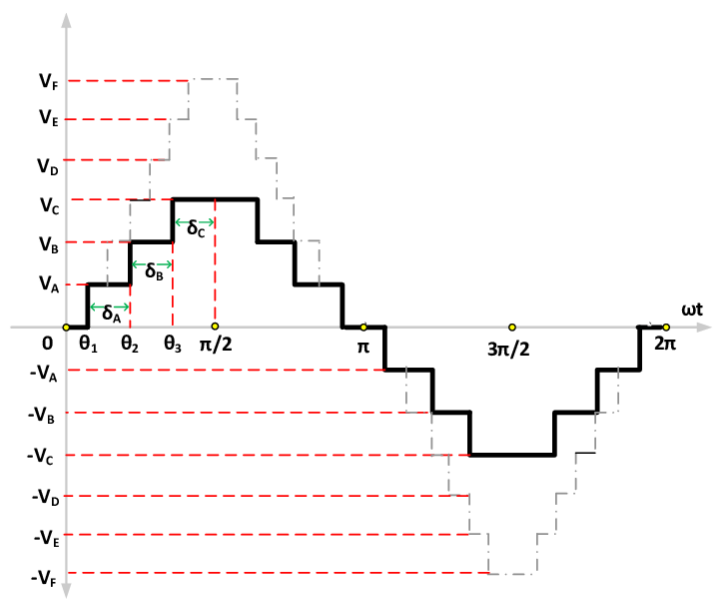

Figure 3 General output voltage waveform.

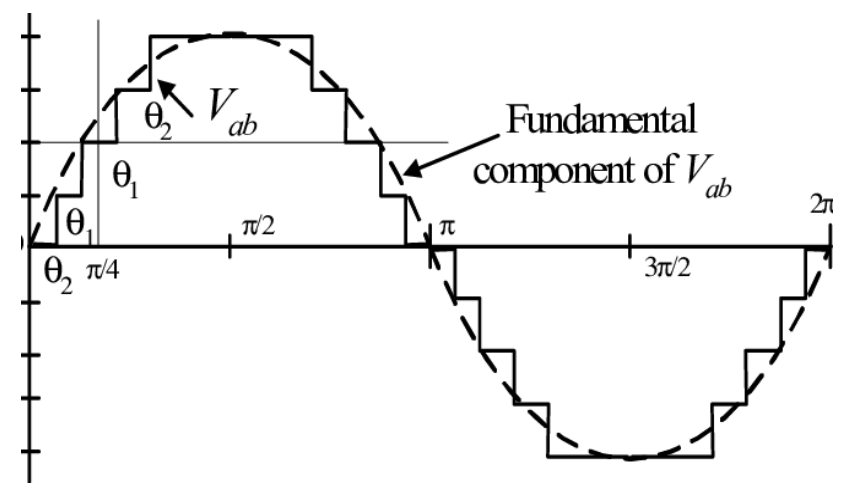

Figure 4 Nine level output waveform.
The switching angles are indicted in above figure. The aim of this step is to find the values of those angles such that the selected harmonics are mitigated.

The Figure 3 shows the $\mathrm{H}$ bridge circuit. This can generate three levels in output voltage waveform. The switching tables to generate three voltage levels are shown in Table 1 , which is shown below.

The harmonics to eliminate in this work are third, fifth, and seventh order harmonics. A nine level inverter consists of four bridges, so there will be four switching angles in first quarter cycle. So maximum there are four degrees of freedom. Which means maximum of any four harmonics can be eliminated using those four degrees of freedom.

\subsection{Writing the Equations}

The magnitude of all the voltage sources is equal as the MLI is symmetrical. Hence it is written as

$$
V_{1}^{*}=V_{2}^{*}=V_{3}^{*}=V_{4}^{*}=V^{*}=\frac{V}{V_{d c}}
$$

The switching angles that need to be calculated are follows the condition below.

$$
\begin{aligned}
& 0<\alpha_{k}<\frac{\pi}{2}, \quad k=1,2,3,4 \\
& \left\{\begin{array}{l}
\cos \left(3 \alpha_{1}\right)+\cos \left(3 \alpha_{2}\right)+\cos \left(3 \alpha_{3}\right)+\cos \left(3 \alpha_{4}\right)=0 \\
\cos \left(5 \alpha_{1}\right)+\cos \left(5 \alpha_{2}\right)+\cos \left(5 \alpha_{3}\right)+\cos \left(5 \alpha_{4}\right)=0 \\
\cos \left(7 \alpha_{1}\right)+\cos \left(7 \alpha_{2}\right)+\cos \left(7 \alpha_{3}\right)+\cos \left(7 \alpha_{4}\right)=0
\end{array}\right.
\end{aligned}
$$

In above expression (3), the first equation is for third harmonic, second one is for fifth harmonic, and the last one is for seventh harmonic.

By simplifying the above equations, we get following expressions.

$$
\left\{\begin{array}{l}
2 \cos \left(\frac{3}{2}\left(\alpha_{1}+\alpha_{2}\right)\right) \cos \left(\frac{3}{2}\left(\alpha_{1}-\alpha_{2}\right)\right)+ \\
+2 \cos \left(\frac{3}{2}\left(\alpha_{3}+\alpha_{4}\right)\right) \cos \left(\frac{3}{2}\left(\alpha_{3}-\alpha_{4}\right)\right)=0 \\
2 \cos \left(\frac{5}{2}\left(\alpha_{1}+\alpha_{2}\right)\right) \cos \left(\frac{5}{2}\left(\alpha_{1}-\alpha_{2}\right)\right)+ \\
+2 \cos \left(\frac{5}{2}\left(\alpha_{3}+\alpha_{4}\right)\right) \cos \left(\frac{5}{2}\left(\alpha_{3}-\alpha_{4}\right)\right)=0 \\
2 \cos \left(\frac{7}{2}\left(\alpha_{1}+\alpha_{2}\right)\right) \cos \left(\frac{7}{2}\left(\alpha_{1}-\alpha_{2}\right)\right)+ \\
+2 \cos \left(\frac{7}{2}\left(\alpha_{3}+\alpha_{4}\right)\right) \cos \left(\frac{7}{2}\left(\alpha_{3}-\alpha_{4}\right)\right)=0
\end{array}\right.
$$

So, by again the above equations will become

$$
\left\{\begin{array}{l}
\alpha_{1}+\alpha_{2}=\frac{\pi}{3} \\
\alpha_{3}+\alpha_{4}=\frac{\pi}{3} \\
2 \cos \left(\frac{5 \pi}{6}\right)\left[\cos \left(\frac{5}{2}\left(\alpha_{1}-\alpha_{2}\right)\right)+\cos \left(\frac{5}{2}\left(\alpha_{3}-\alpha_{4}\right)\right)\right]=0 \\
2 \cos \left(\frac{7 \pi}{6}\right)\left[\cos \left(\frac{7}{2}\left(\alpha_{1}-\alpha_{2}\right)\right)+\cos \left(\frac{7}{2}\left(\alpha_{3}-\alpha_{4}\right)\right)\right]=0
\end{array}\right.
$$

By further simplifying the above equation, we obtain

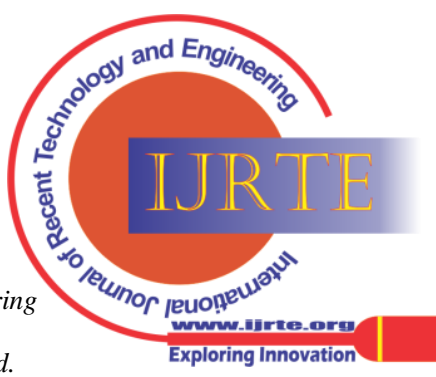




$$
\begin{aligned}
& \left\{\begin{array}{l}
\alpha_{1}+\alpha_{2}=\frac{\pi}{3} \\
\alpha_{3}+\alpha_{4}=\frac{\pi}{3} \\
4 \cos \left(\frac{5 \pi}{6}\right) \cos \left(\frac{5}{2}\left(\frac{\alpha_{1}-\alpha_{2}+\alpha_{3}-\alpha_{4}}{2}\right)\right) \\
\cos \left(\frac{5}{2}\left(\frac{\alpha_{1}-\alpha_{2}-\alpha_{3}+\alpha_{4}}{2}\right)\right)=0 \\
4 \cos \left(\frac{7 \pi}{6}\right) \cos \left(\frac{7}{2}\left(\frac{\alpha_{1}-\alpha_{2}+\alpha_{3}-\alpha_{4}}{2}\right)\right) \\
\cos \left(\frac{7}{2}\left(\frac{\alpha_{1}-\alpha_{2}-\alpha_{3}+\alpha_{4}}{2}\right)\right) \stackrel{2}{=} 0
\end{array}\right. \\
& \left\{\begin{array}{l}
\alpha_{1}+\alpha_{2}=\frac{\pi}{3} \\
\alpha_{3}+\alpha_{4}=\frac{\pi}{3} \\
\alpha_{1}-\alpha_{2}+\alpha_{3}-\alpha_{4}=\frac{2 \pi}{5} \\
4 \cos \left(\frac{7 \pi}{6}\right) \cos \left(\frac{7 \pi}{10}\right) \cos \left(\frac{7}{2}\left(\frac{\alpha_{1}-\alpha_{2}-\alpha_{3}+\alpha_{4}}{2}\right)\right)=0
\end{array}\right. \\
& \left\{\begin{array}{l}
\alpha_{1}+\alpha_{2}=\frac{\pi}{3} \\
\alpha_{3}+\alpha_{4}=\frac{\pi}{3} \\
\alpha_{1}-\alpha_{2}+\alpha_{3}-\alpha_{4}=\frac{2 \pi}{5} \\
\alpha_{1}-\alpha_{2}-\alpha_{3}+\alpha_{4}=\frac{2 \pi}{7}
\end{array}\right.
\end{aligned}
$$

The above (8) can be written in matrix form as

$$
\left(\begin{array}{cccc}
1 & 1 & 0 & 0 \\
0 & 0 & 1 & 1 \\
1 & -1 & 1 & -1 \\
1 & -1 & -1 & 1
\end{array}\right)\left(\begin{array}{l}
\alpha_{1} \\
\alpha_{2} \\
\alpha_{3} \\
\alpha_{4}
\end{array}\right)=\left(\begin{array}{c}
\frac{\pi}{3} \\
\frac{\pi}{3} \\
\frac{2 \pi}{5} \\
\frac{2 \pi}{7}
\end{array}\right)
$$

By solving the above expressions, angles can be obtained. These angles can be used as an initial guess to find the optimal switching angles which results in minimization of the selected harmonics.

\subsection{Solving the Equations}

Various algorithms can be used to solve the equations that are derived in the previous section. All the equations are non linear in nature and results in different solutions. Below Table I give the list of various methods that can used to solve the nonlinear equation in SHE method.

Table I Various methods for SHE.

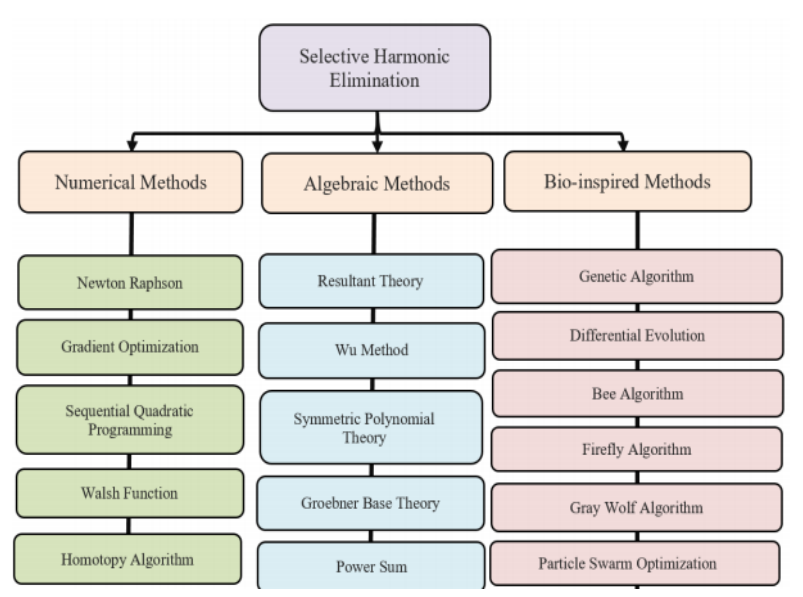

In this work, the Newton Raphson method is employed in solving the nonlinear equations derived in previous section. By applying the Newton Raphson, directly the

Published By:

III. NINE LEVEL CHB MLI

In this section the structure and the operation of a 9 level CHB MLI is presented. The switching states are also shown. Figure 5 shows the circuit topology of the 9 level

MLI.

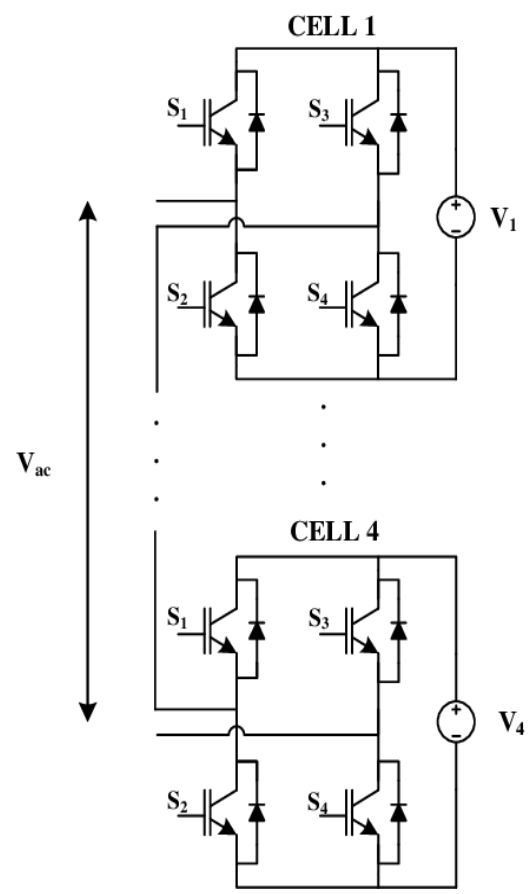

Figure 5 Nine level CHB MLI.

\section{Gate Pulse Generation}

step the gate pulses are generated using any angles shown in Table II. These pulses will be applied to the 9 level MLI.

\begin{tabular}{c|c}
$m$ & Switching angles [rad] \\
\hline 0.3 & $4.429 \cdot 10^{-1}, 1.071,1.490,2.118$ \\
0.4 & $3.417 \cdot 10^{-1}, 9.700 \cdot 10^{-1}, 1.389,2.017$ \\
0.5 & $2.360 \cdot 10^{-1}, 8.644 \cdot 10^{-1}, 1.283,1.912$ \\
0.6 & $1.239 \cdot 10^{-1}, 7.522 \cdot 10^{-1}, 1.171,1.799$ \\
0.7 & $2.193 \cdot 10^{-3}, 6.305 \cdot 10^{-1}, 1.049,1.678$ \\
0.8 & $1.347 \cdot 10^{-1}, 4.936 \cdot 10^{-1}, 9.125 \cdot 10^{-1}, 1.541$ \\
0.9 & $2.987 \cdot 10^{-1}, 3.296 \cdot 10^{-1}, 7.485 \cdot 10^{-1}, 1.377$ \\
1 & $9.648 \cdot 10^{-2}, 5.154 \cdot 10^{-1}, 5.318 \cdot 10^{-1}, 1.144$
\end{tabular}

The above table II shows the list of four switching angles y . . . 
The MLI under study consists of four H-bridges. Each bridge consists of four switches. Each bridge alone can generate three levels and altogether it will generate 9 levels, in which four are positive, four are negative, and a zero level.

The magnitude of DC voltage sources is equal. All the four bridges are connected in cascaded mode. Various switches are responsible for generation of various levels. It can generate positive as well as negative levels. More options are available for generating zero voltage level.

Table III Switching states of switches.

\begin{tabular}{|l|l|l|l|l|l|l|l|l|}
\hline Levels & $\mathbf{S}_{1}$ & $\mathbf{S}_{2}$ & $\mathbf{S}_{3}$ & $\mathbf{S}_{4}$ & $\mathbf{S}_{5}$ & $\mathbf{S}_{6}$ & $\mathbf{S}_{7}$ & $\mathbf{S}_{8}$ \\
\hline $\mathbf{0}$ & ON & OFF & ON & OFF & ON & OFF & ON & OFF \\
\hline $\mathbf{V}_{\mathrm{dc}}$ & ON & ON & OFF & OFF & ON & OFF & ON & OFF \\
\hline $\mathbf{2} \mathbf{V}_{\mathrm{dc}}$ & OFF & OFF & ON & ON & ON & ON & OFF & OFF \\
\hline $\mathbf{3} \mathbf{V}_{\mathrm{dc}}$ & ON & OFF & ON & OFF & ON & ON & OFF & OFF \\
\hline $\mathbf{4} \mathbf{V}_{\mathrm{dc}}$ & ON & ON & OFF & OFF & ON & ON & OFF & OFF \\
\hline $\mathbf{0}$ & OFF & ON & OFF & ON & OFF & ON & OFF & ON \\
\hline$-\mathbf{V}_{\mathrm{dc}}$ & OFF & OFF & ON & ON & OFF & ON & OFF & ON \\
\hline$-\mathbf{2} \mathbf{V}_{\mathrm{dc}}$ & ON & ON & OFF & OFF & OFF & OFF & ON & ON \\
\hline$-\mathbf{3} \mathbf{V}_{\mathrm{dc}}$ & OFF & ON & OFF & ON & OFF & OFF & ON & ON \\
\hline$-\mathbf{4} \mathbf{V}_{\mathrm{dc}}$ & OFF & OFF & ON & ON & OFF & OFF & ON & ON \\
\hline
\end{tabular}

The switching states of various switches are shown in Table III, which is shown above. At max four switches are ON to generate any one particular level.

\subsection{THD Calculation}

The measure for the power quality is THD. So it is very important to find the THD of any waveform, in particular for the voltage waveform of a MLI.

The THD can be computed by following expression

$$
\mathrm{THD} \%=\frac{\sqrt{\sum_{n=3,5}^{49} H_{n}^{2}}}{H_{1}} 100
$$

In above expression, The $\mathrm{H}$ is the harmonic order. $\mathrm{H}_{1}$, $\mathrm{H}_{2}, \mathrm{H}_{3}, \ldots \ldots$ represents the fundamental, second order, and third order harmonic components respectively. The THD is expressed in percentage, and also all the harmonics will be expressed as the percentage values.

\section{SIMULATION RESULTS}

All the simulations result that are obtained presented in this section. All the simulation studies are carried out in SIMULINK tool. The value of the resistance is $160 \mathrm{ohm}$ and the inductance is $18.5 \mathrm{mH}$. The switching angles are computed by SHE method, and the gate pulses are applied according to the calculated switching angles.

Figure 6 shows the simulation circuit of a 9 level CHB MLI considered for the study.

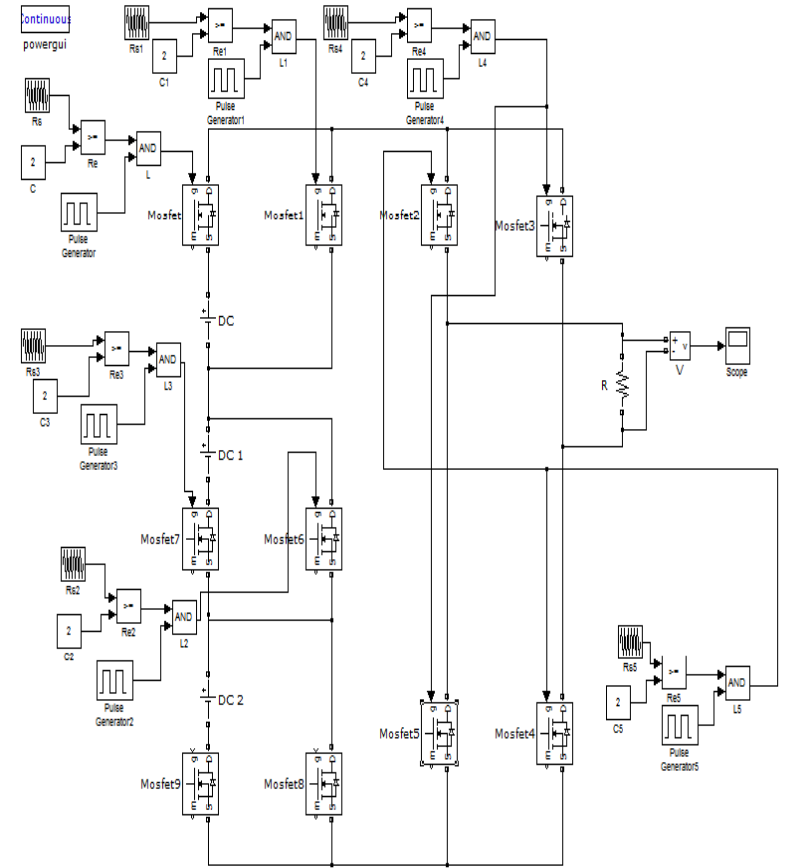

Figure 6 NINE Level MLI.

The 9 level MLI is shown above, which employs the semiconductor switches as main switching element. The circuit is simulated for RL load. The load voltage wave forms and the harmonic spectrums are shown below.

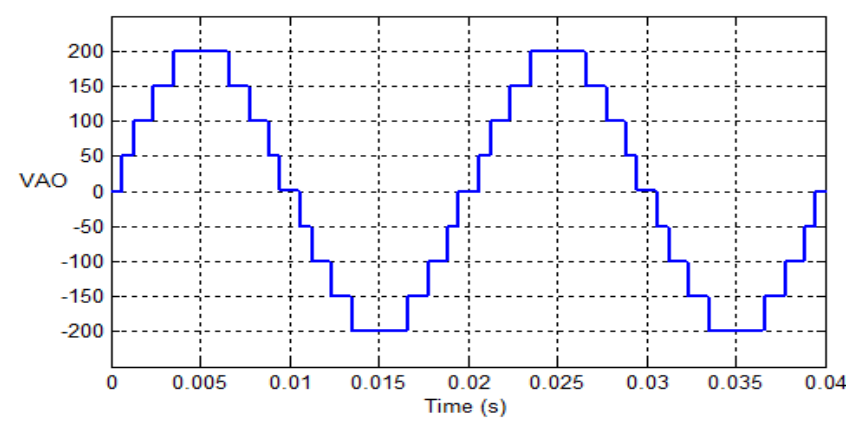

Figure 7 Load Voltage.

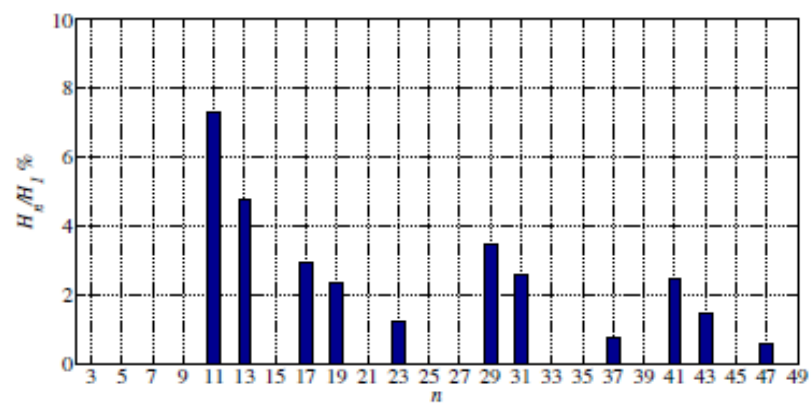

Figure 8 FFT of output voltage.

From the Figure 7 and Figure 8 , the third, firth, and seventh order harmonics are eliminated that is why the values corresponding to it are shown as zero in figures.

Published By:

Blue Eyes Intelligence Engineering

and Sciences Publication

(C) Copyright: All rights reserved.

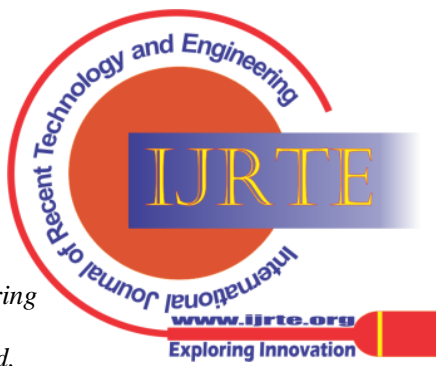




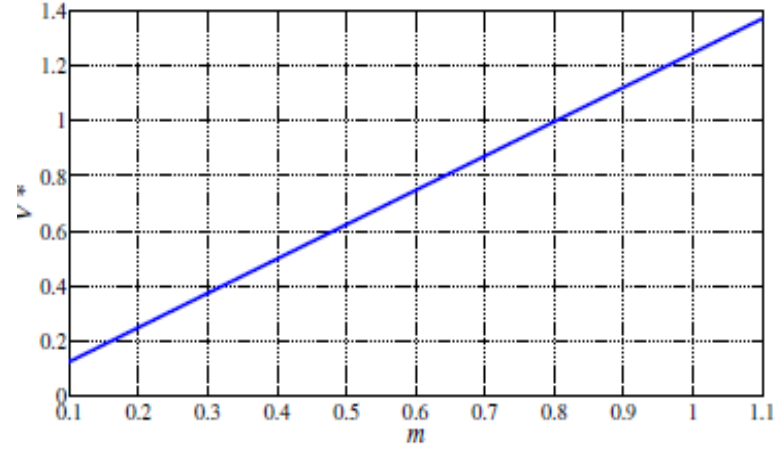

Figure 9 Source Voltage with modulation index.

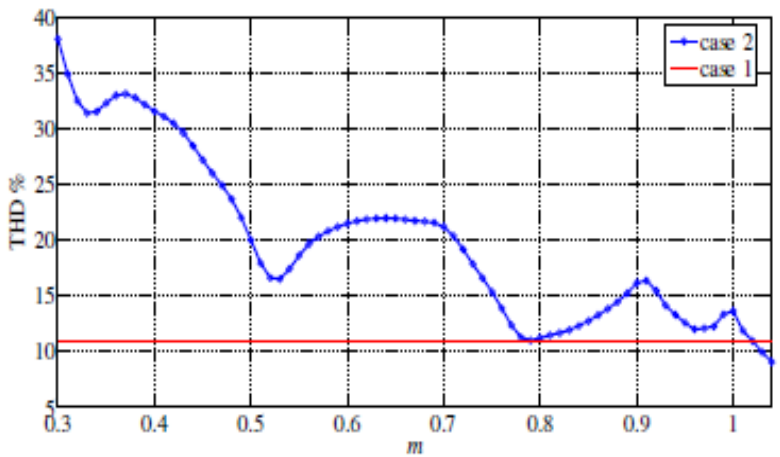

Figure 10 THD with modulation index.

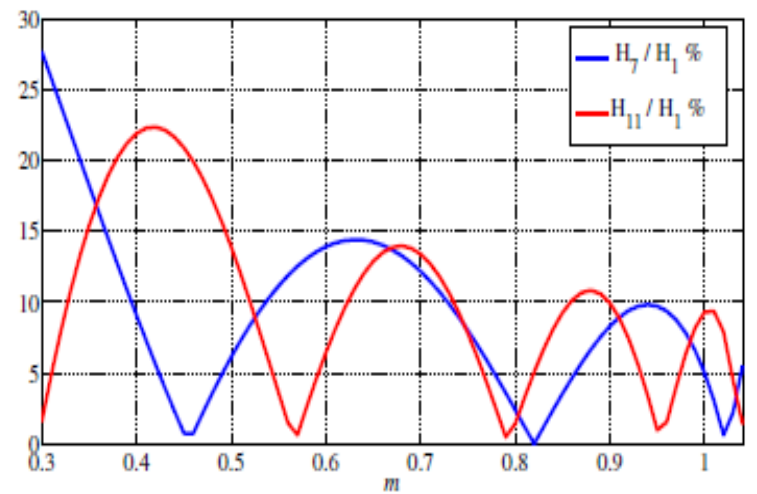

Figure 11 7th and 11th order harmonics.

The THD computed for 9 level MLI is equal to the $11.78 \%$. Due to the elimination of low harmonics, the magnitudes of $\mathrm{H} 3, \mathrm{H} 5$, and $\mathrm{H} 7$ is equal to zero. Which means the SHE method successfully eliminated the selected lower order harmonics from the output waveform of the MLI.

\section{CONCLUSION}

The performance of the nine level CHB MLI with SHE method is evaluated and the results are presented in this paper. Three lower order harmonics are successfully eliminated from the output waveform. From the simulations results it is verified that the SHE method is very effective in eliminating the selected lower order harmonics from the output voltage waveform. Hence, this method can be employed in any inverter, where ever the mitigation of the harmonics is necessary.

\section{REFERENCES}

1. Memon, M. A., Mekhilef, S., \& Mubin, M. (2018). Selective harmonic elimination in multilevel inverter using hybrid APSO algorithm. IET Power Electronics, 11(10), 1673-1680.
2. Panda, K. P., \& Panda, G. (2018). Application of swarm optimisation-based modified algorithm for selective harmonic elimination in reduced switch count multilevel inverter. IET Power Electronics, 11(8), 1472-1482.

3. Ahmed, M., Orabi, M., Ghoneim, S. S., Al-Harthi, M. M., Salem, F. A., Alamri, B., \& Mekhilef, S. (2019). General mathematical solution for selective harmonic elimination. IEEE Journal of Emerging and Selected Topics in Power Electronics, 8(4), 44404456.

4. Kumle, A. N., Fathi, S. H., Jabbarvaziri, F., Jamshidi, M., \& Yazdi, S. S. H. (2015). Application of memetic algorithm for selective harmonic elimination in multi-level inverters. IET Power Electronics, 8(9), 1733-1739.

5. Riad, N., Anis, W., Elkassas, A., \& Hassan, A. E. W. (2021). ThreePhase Multilevel Inverter Using Selective Harmonic Elimination with Marine Predator Algorithm. Electronics, 10(4), 374.

6. Kumar, N. V., Chinnaiyan, V. K., Pradish, M., \& Divekar, M. S. (2016). Selective harmonic elimination: An comparative analysis for seven level inverter. In 2016 IEEE Students' Technology Symposium (TechSym) (pp. 157-162). IEEE

7. Haghdar, K., \& Shayanfar, H. A. (2018). Selective harmonic elimination with optimal DC sources in multilevel inverters using generalized pattern search. IEEE Transactions on Industrial Informatics, 14(7), 3124-3131.

8. Routray, A., Singh, R. K., \& Mahanty, R. (2019). Selective harmonic elimination and balancing of capacitor voltage in hybrid cascaded multilevel inverter using model predictive control. In 2019 IEEE Energy Conversion Congress and Exposition (ECCE) (pp. $2597-$ 2602). IEEE.

9. Haghdar, K. (2019). Optimal DC source influence on selective harmonic elimination in multilevel inverters using teachinglearning-based optimization. IEEE Transactions on Industrial Electronics, 67(2), 942-949.

10. Memon, M. A., Mekhilef, S., Mubin, M., \& Aamir, M. (2018) Selective harmonic elimination in inverters using bio-inspired intelligent algorithms for renewable energy conversion applications: A review. Renewable and Sustainable Energy Reviews, 82, 22352253.

11. Gopal, Y., Birla, D., \& Lalwani, M. (2018). Selected harmonic elimination for cascaded multilevel inverter based on photovoltaic with fuzzy logic control maximum power point tracking technique. Technologies, 6(3), 62.

12. Al-Hitmi, M., Ahmad, S., Iqbal, A., Padmanaban, S., \& Ashraf, I. (2018). Selective Harmonic Elimination in a Wide Modulation Range Using Modified Newton-Raphson and Pattern Generation Methods for a Multilevel Inverter. energies, 11(2), 458.

\section{AUTHORS PROFILE}

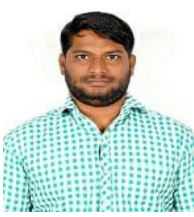

Mr.K Venkateswara Rao, is pursuing MTech( Powe electronics) in Raghu Institute of Technology (Autonomous) Visakhapatnam. He obtained B.Tech (Electrical and Electronics Engineering)

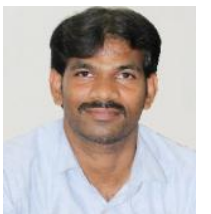

Dr. G Joga Rao, is working as an associate professor in the department of EEE, Raghu Institute of Technology (Autonomous) Visakhapatnam. He obtained B.Tech (Electrical Engineering) and MTech (Electrical Power Engineering) degree from J.N.T University, Hyderabad, in 2004 and 2007 respectively. He completed his doctoral program from S.R University, India in 2017. He has more than 15 years of teaching experience in various colleges and published more than 50 publications in various reputed international journals. His area of interest includes Energy Systems, Power Electronics and Renewable Energy Technologies. He is a life member of the Indian Society for Technical Education and Institute of Engineers IE.

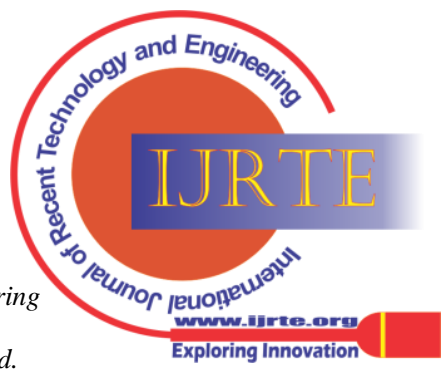

